\title{
Diabetic Mario: Designing and Evaluating Mobile Games for Diabetes Education
}

\author{
Nilufar Baghaei, PhD,', David Nandigam, MSc, John Casey, PhD,1 \\ Artur Direito, $\mathrm{PhD}^{2}$, and Ralph Maddison, $\mathrm{PhD}^{2,3}$
}

\begin{abstract}
Traditionally, diabetes education has relied on written materials, with limited resources available for children with diabetes. Mobile games can be effective and motivating tools for the promotion of children's health. In our earlier work, we proposed a novel approach for designing computer games aimed at educating children with diabetes. In this article, we apply our game design to a mobile Android game (Mario Brothers). We also introduce four heuristics that are specifically designed for evaluating the mobile game, by adapting traditional usability heuristics. Results of a pilot study $(n=12)$ to evaluate gameplay over 1 -week showed that the children found the game engaging and improved their knowledge of healthy diet and lifestyle.
\end{abstract}

\section{Introduction}

T N LIGHT OF THE increasing prevalence of diabetes (estimated to be over 240,000 New Zealanders*), addressing this condition is a public health priority. Diabetes is a major preventable cause of costly and debilitating renal failure, heart disease, lower limb amputation, and avoidable blindness; it is also a major contributor to inequalities in life expectancy. ${ }^{1}$

Children with diabetes in New Zealand receive medical care from a physician-coordinated team of nurses, dieticians, and health psychologists with a special interest in diabetes. This approach is resource intensive and potentially could benefit from an inexpensive, popular new mode of delivering diabetes health-related education. Existing research evidence supports the use of videogames to promote health-related behaviors. A randomized controlled trial, which provided health behavior information and support in the form of a videogame, helped children aged 10-12 years consume more fruits and vegetables. ${ }^{2}$ A systematic review of interactive multimedia interventions to educate children about their health demonstrated potential to improve children's health-related self-efficacy, which could in turn enable them to become more competent on complex topics such as dietary behavior change discussions. ${ }^{3}$

*New Zealand Ministry of Health. www.health.govt.nz/your-health/ conditions-and-treatments/diseases-and-illnesses/diabetes (accessed in October 2015).
Playing games with mobile devices have become increasingly popular both in the development of games and in the field of research. The use of smartphones and tablet computers may offer opportunities to engage young people during inactive times between visits to the healthcare professionals, tests, or treatments by providing interactive health education modules. ${ }^{4}$ Mobile technologies offer the potential for a new phase in the evolution of technology-enhanced learning. As the current research points out (e.g., Chai et al. ${ }^{26}$ ), meaningful learning could take place when learners are engaged in activities that allow for experimentation, conversation, collaboration, and reflection. Using mobile games for exploring new ways of learning has been shown to be very promising. Mobile gaming could be very well used in creating authentic and engaging activities that combine teaching and gaming. ${ }^{30}$ Informal learning coupled with games can provide a foundation for innovation when applied to more formal learning situations.

According to Kirriemuir, ${ }^{18}$ there are two key themes common to the development of games for education: (1) the desire to harness the motivational power of games to "make learning fun"; and (2) a belief that "learning through doing" in the form of games offers a powerful learning experience. It has been proposed that the real educational value of a computer game should be exemplified by its ability of creating a playful learning experience for children through experimentation, progressive exploration, trial and error, imagination, role play, and simulation. Therefore, a game designed

\footnotetext{
${ }^{1}$ Unitec Institute of Technology, Auckland, New Zealand.

${ }^{2}$ National Institute for Health Innovation, The University of Auckland, Auckland, New Zealand.

${ }^{3}$ Institute for Physical Activity and Nutrition, Deakin University Geelong, Australia.
} 
to satisfy these criteria might provide a useful platform for education. Based on this understanding, learning in a computer game should be purposely structured through a series of exploration tasks so that children can discover essential diabetes knowledge in a progressive and experimental manner.

Driven by the initiative of the Adult \& Pediatric Diabetes Psychology Service of New Zealand, research has been undertaken to design and develop proactive mechanisms for diabetes education. To enhance children's learning about their condition, we chose to focus on exploiting interactive features of computer games to deliver education knowledge through immersive and situational learning. As a result, we embarked on developing a novel game design for teaching children how to manage their diabetes. ${ }^{5}$ In this article, we applied the proposed design ideas to an open-source 2D game (Mario Brothers), developed a mobile version, and conducted a pilot study with 12 children to determine the effects of playing the game on enhancing children's knowledge of healthy diet and lifestyle. We also present four heuristics specifically designed for evaluating educational mobile games.

The rest of the article is structured as follows. Designing Mobile Games for Diabetes Education and Game Modification for Diabetes Education sections describe the game design and implementation process and its features. Pilot Study section presents the pilot study and reports our initial findings. Conclusions and Future Work section conclude the article and highlight future research opportunities.

\section{Designing Mobile Games for Diabetes Education}

\section{Research questions}

The main aim of this project is to investigate how we can effectively embed diabetes knowledge in a computer game to engage children for immersive learning. Two research questions are, therefore, investigated: (1) will engagement with the mobile game result in gaining greater knowledge of healthy diet and lifestyle? (2) how engaged are the participants with the game and what is their perception? We hypothesized that the participants will enjoy playing the game and that game-based support will enhance the diabetes health-related knowledge, which in turn can stimulate and facilitate the conversation of the children with healthcare providers about their self-management practices.

\section{Design strategies}

To address these questions, the very nature of computer games needs to be carefully examined. The key concept that is frequently utilized to explain the level of engagement in a computer game is that of "flow," first introduced by Csikszentmihalyi. ${ }^{19}$ Many researchers consider flow as the state of intensive involvement. It is widely believed that flow is the key to the success of an educational game. According to Malone ${ }^{20}$ several conditions are likely to induce the flow state. Among them, a few conditions are of particular importance for designing diabetes education games ${ }^{5}$ :

$\mathrm{C} 1$ : The activities in a game should be structured so that the level of difficulty of the game can be adjusted to match children's diabetes knowledge.

C2: The activities in a game should provide concrete feedback to children so that they can tell how well they per- form and perhaps what they need to do to perform better. In particular, the performance of the game should be closely related to children's skill of managing their diabetic condition.

C3: The activities in a game should present a variety of challenges such that children can obtain increasingly complex information about different aspects of managing their diabetic condition.

It can be argued based on Malone's conditions that, instead of aiming for a gaming experience that superficially conceal the educational purpose behind fun activities, a careful design of the structure of the game is highly desirable. Specifically, the game structure should contribute to the flow, and subsequently, the creation of an active learning environment.

Consistent with Malone's conditions, we reviewed a host of open-source games ${ }^{5}$ to identify the most suitable for addressing our requirements. The Mario Brothers game was selected for our game design as it aligns well with the three conditions (i.e., C1, C2, and C3). Our choice was also informed by the following points:

(1) The Mario Brothers game has long been considered as an engaging game for children thanks to its structured design with varied levels of difficulties. Thus, condition $\mathrm{C} 1$ is satisfied.

(2) The Mario Brothers game has built-in feedback mechanisms that allow children to explore various game-play strategies through proactive interaction within a simulated environment. It hereby satisfies condition $\mathrm{C} 2$.

(3) The Mario Brothers game presents a variety of challenges through its stage-based design. It is easy to embed increasingly complex knowledge about living with diabetes at different game-playing stages. Thus, the game agrees well with condition $\mathrm{C} 3$ and is suitable for providing an enduring and fun-filled learning experience.

(4) The Mario Brothers game is open source. A Java version of the game is available for free modification. The game can be easily migrated to different computing platforms, including mobile systems. For this study, we used an Android platform.

(5) The Mario Brothers game has been a popular game for children for decades. Children's and even their parents' familiarity with the game means short learning curve and perhaps wide acceptability.

Although our implementation of the education features was based on this game, we believe that the design strategies as explained below are generic enough to be applied to more educational games. It is worthwhile to mention that these strategies (proposed in our earlier work ${ }^{5}$ ) can be considered as natural consequences of Malone's conditions.

The first strategy is what we call the Structure Enhancement (SE). This means that the inclusion of education features should enhance rather than weaken the game structure. For example, adding education features to a game should contribute to the creation of a series of fine-grained difficulty levels so that children can gain new knowledge progressively as they progress from one level to another.

The second strategy, Feedback Enhancement (FE), refers to the education features providing knowledge-rich visual 
feedback. The triggering of this feedback is likely to be situational and subject to certain properties of the game character. Feedback can assume various forms, with message boxes and on-screen performance indicators being a few examples.

The third strategy is termed the Challenge Enhancement (CE). According to this strategy, education features in a game should present the user with a variety of challenges while they play the game. This is because challenge encourages proactive knowledge discovery and, therefore, enhances engaged learning. A stage-based game design facilitates CE and progressive learning. Using this game design, simple educational features can be embedded in early stages of a game, where complex features are reserved for later stages of the game.

\section{Heuristics}

A good gaming experience requires a lot from the user interface. It should be convenient, reliable, and usable so that the player can concentrate on playing the game and enjoying it instead of struggling with the user interface. ${ }^{25}$ The game design itself has an impact on the gaming experience as well. ${ }^{11}$ If the rules or game world contains implausible features, the players can be easily offended or frustrated and quit playing.

A number of usability heuristics have been proposed for evaluating digital games over the years. ${ }^{6-17}$ The initial set of heuristics proposed by Malone ${ }^{6}$ was categorized into three types as follows: challenges, fantasy, and curiosity. Clanton ${ }^{7}$ proposed 15 heuristics with the main aim being whether or not the game design facilitates user interest. Federoff ${ }^{8}$ proposed a list of 40 heuristics that focused on gameplay, engagement, and storyline elements. Desurvire et al. ${ }^{9}$ proposed heuristics in four categories as follows: game-play, gamestory, game-mechanics, and game-usability. Korhonen and Koivisto $^{11}$ proposed 29 heuristics categorized in terms of "Game-Usability," "Game-Mobility," and "Game-Play." "Game-Play" defines a user's interaction with other objects in the game. "Game-Mobility" defines how easily a player is involved in the game's venue and how it behaves under unclear conditions. "Game-Usability" covers a player's interaction with the game's world and with other players. Schaffer ${ }^{12}$ introduced heuristics for Game-Usability and divided them into five categories as follows: General, Graphical User Interface, Gameplay, Control Mapping, and Level Design. Ibrahim et al. highlighted certain educational playability heuristics for measuring the experience obtained by the players during a game. Shoukry et al. ${ }^{17}$ proposed a framework for evaluating mobile educational games in 15 categories ranging from screen design, navigation, and ease of use to customization, security, and accessibility.

Having reviewed the heuristics for the evaluation of videogames for the last 20 years, we felt that most of the heuristics proved very generic and valid only for high-level game issues. In addition, some were not validated. In heuristic validation, each heuristic is evaluated according to its relevance in designating usability problems..$^{21-24}$ The heuristics for evaluating games in mobile context are qualitatively different from traditional playability heuristics. The mobile context has some unique characteristics such as portability (mobility), accessibility (generality), and convenience (simplicity). ${ }^{38}$
TABle 1. HeUristics USED FOR UsABILITY OF THE GAME

\begin{tabular}{ll}
\hline GU1 & Audio-visual representation supports the game \\
GU2 & $\begin{array}{l}\text { Screen layout is efficient and visually pleasing } \\
\text { The player understands the terminology }\end{array}$ \\
GU3 & Navigation is consistent, logical, and minimalist \\
GU4 & Control keys are consistent and follow standard \\
GU5 & conventions \\
GU6 & $\begin{array}{c}\text { The game gives feedback on the player's actions } \\
\text { The player cannot make irreversible errors }\end{array}$ \\
GU7 & $\begin{array}{c}\text { The player does not have to memorize things } \\
\text { unnecessarily }\end{array}$ \\
GU9 & The game contains help \\
\hline
\end{tabular}

To measure player perception of our proposed game, we introduce four heuristics, Usability, Educability, Mobility, and Playability:

- The Usability aspect of the heuristics covers audiovisual elements, screen layout, terminology used in the content, navigation, controls offered, feedback management, and the help features (Table 1).

- The Playability heuristics are crucial in deciding how engaging the game is and whether or not the user would come back to playing the game. It includes elements as game controls, game goals, how progress is made, reward structure, game mechanics, and storyline (Table 2).

- The Mobility heuristics represent not only where and when games are played but also how easily the game allows a player to enter into playing the game and how it responds to various unexpected situations and environments (Table 3).

- The Educability heuristics take care of how much of learning has taken place in a specific domain. This is evaluated in terms of several display mechanisms (e.g., the blood sugar indicator), confidence achieved (e.g., easy to control the blood sugar levels), and application of the knowledge (e.g., managing one's own diet as a result) (Table 4).

\section{Game Modification for Diabetes Education}

Driven by the three design strategies, namely SE, FE, and $\mathrm{CE}$, modifications were made to incorporate educational

Table 2. Heuristics Used for Playability OF THE GAME

GP1 The game controls are easy to use

GP2 The game provides clear goals or supports player-created goals

GP3 The player sees the progress in the game and can compare the results

GP4 The players are rewarded and rewards are meaningful

GP5 The players are in control

GP6 The first-time experience is encouraging

GP7 The game story supports the gameplay and is meaningful

GP8 There are no repetitive or boring tasks

GP9 The game is consistent

GP10 The player does not lose any hard-won possessions 
Table 3. Heuristics USED FOR Mobility OF THE GAME

MO1 The game and play sessions can be started quickly

MO2 The game accommodates the surroundings

MO3 Interruptions are handled responsibly

MO4 More time can be spent playing the game because it is on a tablet

features into the mobile Mario Brothers game (Fig. 1). In line with the fundamental principles of role play games, the main character of the game, named Mario, is assumed to have diabetes mellitus. Thus, the health problems faced by Mario become the health problems to be solved by the game player. The ultimate goal of the game is to save a princess who is locked in a castle. To achieve this goal, Mario needs to manage his blood sugar levels while fighting against a variety of evil guards during multiple stages of the game.

It is expected that, as children progress through stages of the game, they will gradually learn the skills to remain healthy by choosing appropriate food options, being physically active, and modulating insulin use. SE, FE, and $\mathrm{CE}$ have been extensively utilized to support effective learning in the game. Below, we discuss some representative examples of using the three strategies.

Example 1: Managing Mario's health through his blood sugar level is designed as a main challenge at every stage of the game. If Mario's blood sugar level goes outside therapeutic levels, the character's effort to rescue the princess will fail. To emphasize the importance of the blood sugar level, an indicator is placed at the top left corner of the game screen. In line with FE, the indicator as shown in Figure 1 is designed to change color whenever Mario's blood sugar level rises or falls. Blood sugar level is determined by numerous factors, including playing time, the amount of exercises Mario performs (e.g, walking, running and jumping), and the foods Mario consumes.

Example 2: The modified Mario Brothers game is designed to help the player gain the requisite knowledge to better manage their condition. As illustrated in Figure 1, choices regarding food consumption or insulin injection will pop up occasionally when Mario's blood sugar level deviates from optimal levels. According to SE, the options essentially represent fine-grained challenges since the player needs to make correct choices through eating healthy food or using insulin to continue playing the game. The choice is driven by Mario's blood sugar level and the progress of the game. The level of difficulty is adjusted to match the player's diabetes knowledge.

Example 3: The challenge of maintaining appropriate blood sugar levels increases as the player progress through

Table 4. Heuristics Used for Educability OF THE GAME

ED1 The blood sugar indicator easy to understand

ED2 Easy to control the blood sugar level

ED3 Seeing Mario going through the blood sugar level changes, you feel confident about managing your own diet

ED4 The game helped understand how blood sugar level changes different stages of the game. Consistent with $\mathrm{CE}$, at an early stage of the game, a small set of recommended food or insulin will be provided when Mario has an abnormal blood sugar level. At later stages of the game, the challenge increases and children need to choose from a variety of options to determine the correct food type or amount of insulin. To make this job even tougher, choices do not appear automatically. Children need to pay constant attention to Mario's blood sugar level while playing the game. Whenever the blood sugar levels are not optimized, the player must bring up the choices menu manually to better control their levels.

\section{Pilot Study}

\section{Design}

A pre-post pilot study was conducted with the modified mobile version of Mario Brothers in January-April 2015. Eligible participants were 12 children aged 9-13 years $(6$ females, 6 males), recruited from the greater Auckland area through community advertisements, schools, and word of mouth (see Table 5 for descriptive characteristics).

For the purpose of this study, participants were not required to have diabetes mellitus, nor had to have any particular experience playing videogames of any time. The study was approved by the University of Auckland Human Participants Ethics Committee (Ref 013217). Participation in the study was entirely voluntary. Interested participants were given a participant information sheet to read and complete written informed consent at baseline data collection.

Assessments were conducted at baseline and 1-week after (post-intervention). At each time point, participants filled out a health-related questionnaire concerning their diet, physical activity, and lifestyle choices. Following the baseline assessment, participants were loaned a Samsung tablet for 1 week so they could play the mobile game in their free time if/when they wanted to. For the purpose of this study, participants were required to login with a unique user ID. The game automatically logged all the interactions, including when and for how long they played each time, which choices they made, how much feedback they received etc. At the end of the week, we collected the tablets and asked them to fill out the healthrelated questionnaire again, followed by a survey with closed and open questions about what they thought of the game.

Table 5. Descriptive Characteristics OF THE PARTICIPANTS

\begin{tabular}{|c|c|c|c|c|c|c|}
\hline No. & $\begin{array}{l}\text { Reg. } \\
\text { No. }\end{array}$ & Gender & Age & Ethnicity & Height & Weight \\
\hline 1 & 003 & $\mathrm{M}$ & 10 & NZ European & 1.53 & 39.3 \\
\hline 2 & 005 & $\mathrm{~F}$ & 10 & Indian & 1.44 & 48.2 \\
\hline 3 & 006 & $\mathrm{M}$ & 10 & NZ European & 1.36 & 31.3 \\
\hline 4 & 007 & $\mathrm{~F}$ & 9 & Indian & 1.35 & 26.8 \\
\hline 5 & 008 & $\mathrm{~F}$ & 13 & Sri Lankan & 1.62 & 66.1 \\
\hline 6 & 009 & M & 10 & Samoan & 1.44 & 39 \\
\hline 7 & 010 & M & 9 & Indian & 1.28 & 27 \\
\hline 8 & 011 & $\mathrm{~F}$ & 12 & NZ European & 1.54 & 48.4 \\
\hline 9 & 013 & $\mathrm{~F}$ & 10 & Indian & 1.34 & 30.8 \\
\hline 10 & 014 & $\mathrm{~F}$ & 9 & Persian & 1.36 & 39 \\
\hline 11 & 016 & M & 12 & Chinese & 1.46 & 32.5 \\
\hline 12 & 017 & M & 10 & Chinese & 1.4 & 48.9 \\
\hline
\end{tabular}




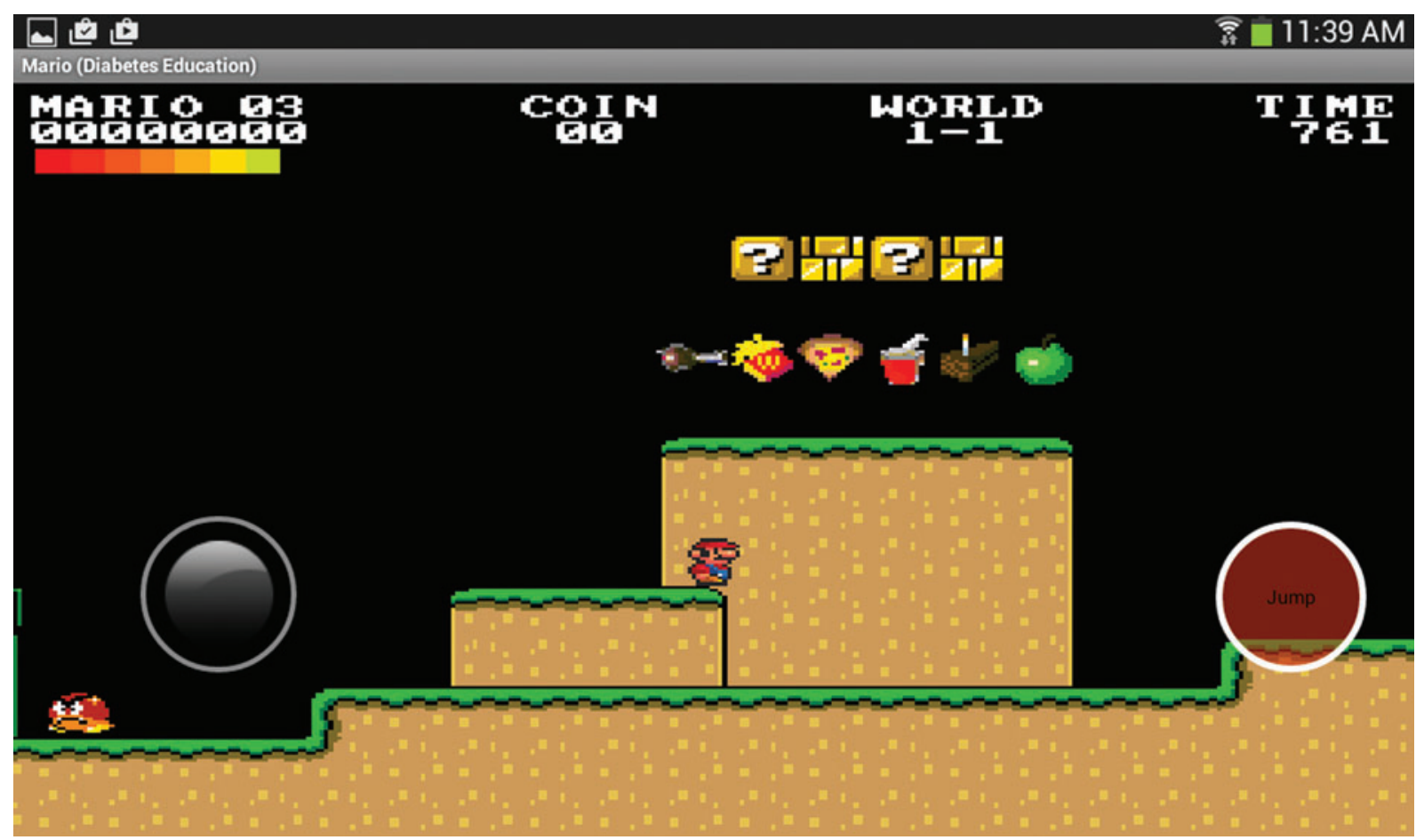

FIG. 1. The screenshot of the Android mobile version-Diabetic Mario should maintain his blood sugar level (shown at the top) while trying to save the princess. (Color graphics available at www.liebertonline.com/g4h)

\section{Evaluation metrics}

The main objectives of this study were to determine the effect of playing the mobile game on enhancing children's knowledge of healthy diet and lifestyle. We also wanted to know whether children found the game engaging over the period of 1 week. Thus, the changes of users' knowledge of healthy diet and lifestyle, as well as their perception of the mobile game, were our dependent variables.

To measure lifestyle knowledge enhancement, we used the health knowledge questionnaire developed by Saksvig et al., ${ }^{27}$ based on previous work from the CATCH Health Behaviors Program ${ }^{28}$ and the Kahnawake Schools Diabetes Prevention Program. ${ }^{29}$ The questionnaire aims to measure change in diet and physical activity psychosocial constructs in children over time. We used a set of questions measuring health-related knowledge (i.e., diet, physical activity, and diabetes) and adjusted the wording of some items to reflect the New Zealand context (e.g., for the originally developed item "Do people in Sandy Lake get more exercise or physical activity today than they did 30 years ago," Sandy Lake was replaced by Auckland). The questionnaire consisted of 21 items about diet and exercise, each with four answer options and took $\sim 10$ minutes to complete. The structure of the questionnaire is presented in Table 6.

The acceptability/perceptions of the game questionnaire were developed by the research team for the purpose of this pilot study. Both questionnaires/surveys were pilot tested in a small sample $(n=2)$ of children of the same age as those to be recruited to ensure reading comprehension of the items. In addition, a research assistant was in place during the completion of the questionnaires, should reading or vocabulary explanations be necessary.
Sample questions were:

What are moderate to vigorous physical activities (tick one only)?

(1) activities we do sitting down

(2) physical activities that give our bodies a workout

(3) physical activities we do for only 5 minutes

(4) I don't know

Which one is the healthiest choice for supper (tick one only)?

(1) lamb meat and macaroni soup, baked crumpet, and water

(2) hot dogs, french fries, jelly, and fizzy or soft drink (e.g., Coke, Sprite, Fanta)

(3) 2 minute noodles, chips, and fruit juice

(4) I don't know

Table 6. The Structure of the Health KNOWLEDGE QUESTIONNAIRE

\begin{tabular}{|c|c|}
\hline Question & Topic of the question \\
\hline Q1 & Awareness of keeping health \\
\hline $\begin{array}{l}\text { Q2, Q3, Q4, Q8, } \\
\text { Q9, Q21 }\end{array}$ & Awareness of healthy food items \\
\hline $\begin{array}{l}\text { Q5, Q6, Q7, Q10, } \\
\text { Q12, Q18 }\end{array}$ & Awareness of unhealthy food items \\
\hline Q11, Q19, Q20 & $\begin{array}{l}\text { Awareness of the benefits of } \\
\text { exercising }\end{array}$ \\
\hline Q13, Q14, Q15, Q17 & $\begin{array}{l}\text { Awareness of diabetes and its } \\
\text { effects on the body }\end{array}$ \\
\hline Q16 & $\begin{array}{l}\text { Awareness of nutrition information } \\
\text { in each food item }\end{array}$ \\
\hline
\end{tabular}


Table 7. Pre and Post Study Statistics

\begin{tabular}{lcclcc}
\hline & \multicolumn{2}{c}{ Average } & & \multicolumn{2}{c}{$S D$} \\
\cline { 2 - 3 } \cline { 5 - 6 } & $\begin{array}{c}\text { Pretest } \\
(\%)\end{array}$ & $\begin{array}{c}\text { Posttest } \\
(\%)\end{array}$ & & $\begin{array}{c}\text { Pretest } \\
(\%)\end{array}$ & $\begin{array}{c}\text { Posttest } \\
(\%)\end{array}$ \\
\hline $\begin{array}{c}\text { Questions related } \\
\text { to healthy food } \\
\text { choices }\end{array}$ & 66 & 77 & & 24 & 16 \\
$\begin{array}{l}\text { Questions related } \\
\text { to exercise }\end{array}$ & 62 & 66 & & 22 & 32 \\
\begin{tabular}{l} 
Overall \\
\hline
\end{tabular} & 65 & 73 & & 12 & 13 \\
\hline
\end{tabular}

To measure player perception of the game, we used four heuristics, Usability, Educability, Mobility, and Playability, as described in Heuristics section.

\section{Results}

On average, participants played the modified Mario Bros game for 20 times over the 1-week period according to the data interaction logs. Out of all participants, two completed all seven levels of the game and the rest completed at least up to level 4.

The analysis of the Health Knowledge Questionnaire reveals that the confidence of the participants increased from pre to post event with respect to selecting healthy eating choices (pre $=66 \%$ to post $=77 \%$ ) and initiating regular exercise habits (pre $=62 \%$ to post $=66 \%$ ). The average score on the post-health questionnaire was higher than the pretest score for all categories (Table 7). All participants agreed that the Mario game experience was an effective method of learning how to manage diabetic condition.
Figure 2a presents the responses to the Usability heuristics. All participants thought that the audio-visual representation supported the game, the terminology was easy to understand, navigation and control keys were consistent, and the player did not have to memorize new terms unnecessarily. Sixty-six percent of users reported that the screen layout was efficient and visually pleasing, 58\% that the game gave appropriate feedback on the player's actions, and $41 \%$ reported that the player cannot make irreversible errors.

Figure $2 \mathrm{~b}$ shows the responses to the Educability heuristics. All participants reported that it was easy for them to control the blood sugar level, $83 \%$ said that they felt confident managing their own diet by seeing Mario going through the blood sugar level changes, and $75 \%$ reported that the blood sugar indicator was easy to understand and that the game helped them understand how the blood sugar level changed.

The responses to Playability heuristics are shown in Figure 2c. All users reported that the game controls were easy to use, the rewards were meaningful, the story supported the gameplay, and that the game was consistent. However, we observed several relatively low scores on some of the Playability heuristics: $41 \%$ of the users thought they can compare results based on their progress in the game, $25 \%$ reported their first-time experience was encouraging, only $17 \%$ of users thought they were in control, and $33 \%$ found the tasks nonrepetitive.

Finally, Figure $2 \mathrm{~d}$ shows the responses to Mobility heuristics. All players thought that the game could be started quickly and believed they would spend more time playing it because it was on a tablet. However, only $41 \%$ reported that the game accommodates with the surroundings and only $33 \%$ felt the interruptions are handled responsibly.
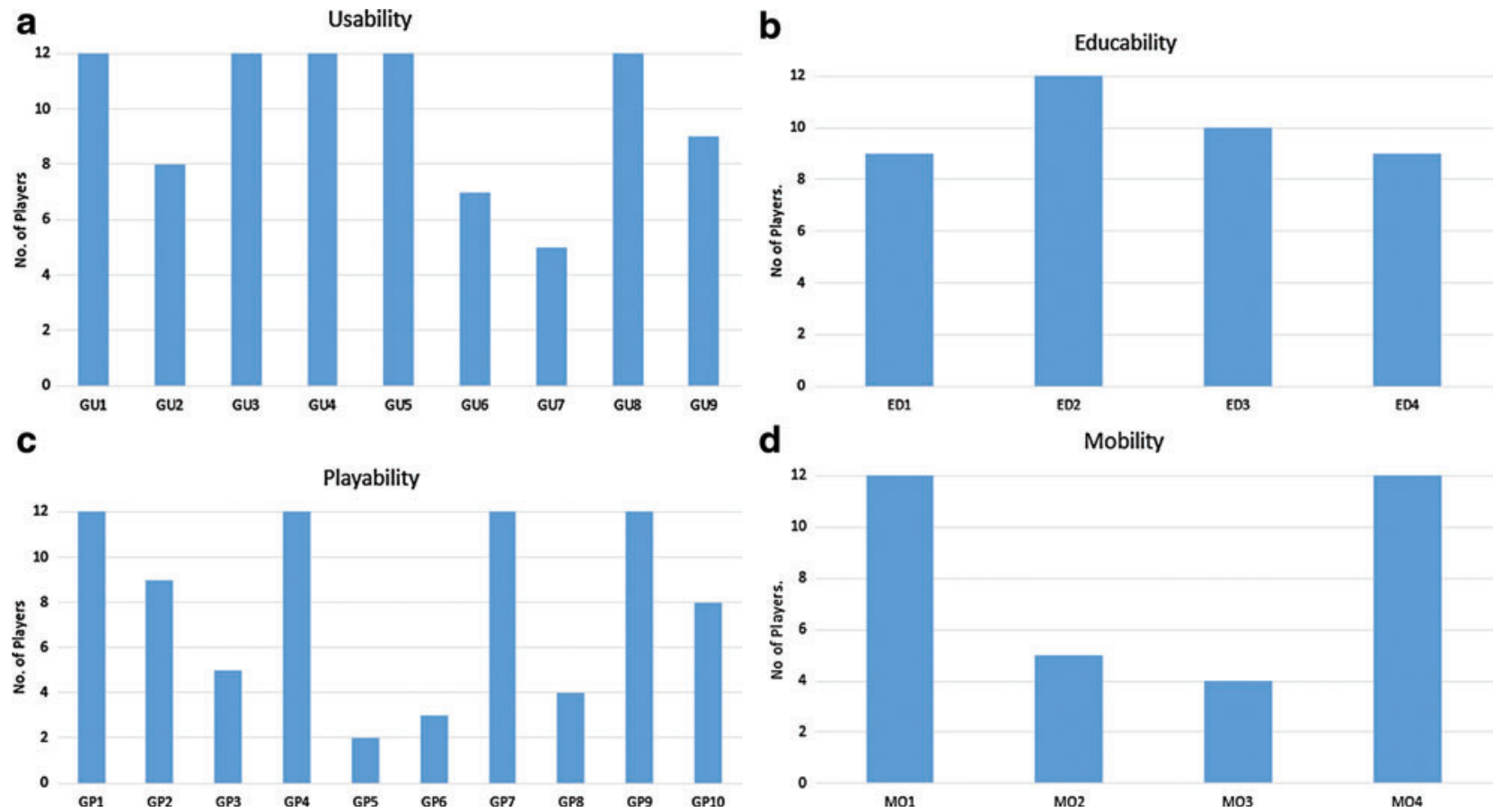

FIG. 2. (a) Responses to the Usability heuristics. (b) Responses to the Educability heuristics. (c) Responses to the Playability heuristics. (d) Responses to the Mobility heuristics. (Color graphics available at www.liebertonline.com/g4h) 


\section{Discussion}

The results show that the participants gained more knowledge of healthy diet and lifestyle as a result of playing the Mario Bros mobile game over a period of 1 week. The analysis of the Health Knowledge Questionnaire reveals that the confidence of the participants increased from pre to post event with respect to selecting healthy eating choices (pre $=66 \%$ to post $=77 \%$ ) and initiating regular exercise habits (pre $=62 \%$ to post $=66 \%$ ). The average score on the post-health questionnaire was higher than the pretest score for all categories. More studies are needed to examine the effect of playing the game on children's knowledge and confidence over a longer period of time.

The results of the Usability heuristics show that in addition to audio-visual features, participants would have liked to see visually pleasing screen especially in terms of the resolution of the animations. Presenting a variety of high resolution images is challenging due to the limited screen resolution of mobile devices used for this research. There was not any terminology used as the game provides the visual representations. Participants found the navigation to be consistent, logical, and minimalist. However, any small error meant starting the game right from the beginning, which may have frustrated some of the users, hence, the relatively low scores for GU6 \& GU7. Some users suggested that there should be new ways to control game characters such as voice interaction.

The results for Educability heuristics show that all players found it easy to control Mario's blood sugar level and majority felt confident managing their own diet by seeing Mario going through the blood sugar level changes. They also reported that the blood sugar indicator was easy to understand and that the game helped them gain a better understanding of how the blood sugar level changed. This was a crucial part of our study, as our final goal is to enable users to take increasing control of their condition.

We believe the results of the Playability heuristics, especially the low scores for GP5, GP6, \& GP8, may have been due to the fact that the participants had to restart the game at Level 1 each time they came back to play it again. Our current version does not record the participant's previous achievement. All seven levels of the game needed to be completed in one session, which was not realistic for a number of players, especially for those who did not have a lot of gaming experience.

The results of the Mobility heuristics were promising. All players thought the game could be started quickly and believed they would spend more time playing it because it was on a tablet. However, only $33 \%$ felt the interruptions are handled responsibly. Feedback is provided on the game-play in terms of sound effects, behavior of the buttons, icons and characters etc, but when the game is finished or interrupted or paused, it does not remember the session details. One participant said, "once the game is off, there is no way that I could know how I did in my previous attempt". Majority of the players liked the fact that they could pause the game and resume it any time and that the game and play sessions could be started almost immediately. However, a few were not happy with the fact that they could not spend more time playing the game, as it was on a tablet (as opposed to a PC, which is what they were used to). The game also crashed on a few occasions. The sudden interruption to the flow of game may have caused disappointment leading to frustration, hence the low MO2 \& MO3 scores.

Overall, the game was viewed as a good and fun experience by the players. We hypothesized that the participants would enjoy playing the game and that game-based support would enhance the diabetes health-related knowledge, which in turn could facilitate the conversation of the children with healthcare providers about their self-management practices. As children progressed through different stages of the game, they gradually learnt the skills to keep Mario's blood sugar level within the optimal levels, thus improving their knowledge of diet healthy lifestyle (as shown by the scores on the posttest questionnaire). The game, therefore, provided practice and showed cause and effect, while also giving them basic information about diabetes self-management.

Based on the results of our study and current literature, ${ }^{31-37}$ we recommend a list of characteristics for an effective health educational game:

- The content of the game should be accurate, graphically detailed, and predictable. Game content development normally requires both aesthetic and technical rendering, and in doing so, the pedagogical requirements of accuracy of content, as well as the predictability, make a game cognitively compliant. For an effective educational experience, the content of the game should be suitable and effective for players of all levels.

- The players should feel that they are in total control of the game. Przybylski et al. ${ }^{31}$ and Rigby and Ryan ${ }^{35}$ argue that digital games promote sustained engagement through meeting players' basic psychological needs of competence, autonomy (freedom of choice based on personal interests), and relatedness (interaction with others).

- The game should respond to players' actions in a consistent, immediate, challenging, and exciting way. There are a number of different ways the game could respond to players' interactions, for example, when playing a game, players seek challenge, mastery, and reward, all packed in entailing and motivating activities. This transmits different stimuli to activate and engage players during playing time.

- The game should make players feel that they are part of a creative and dynamic community. This view is supported by $\mathrm{Chik}^{36}$ that players exercise autonomy by managing their gameplay both as leisure and learning practices in different dimensions (location, formality, locus of control, pedagogy, and trajectory).

- The game should accelerate learning times and focus on reinforcement of players' skills and experience. As games in educational contexts aim to connect between the game world and reality, it would allow the players to accelerate the time taken to absorb key learning outcomes because they make those connections between the two worlds. As a result, it would increase players' retention levels.

\section{Conclusions and Future Work}

This work aimed to exploit the popularity of mobile games in an attempt to impact diabetes health-related knowledge of children. The overall objective of our study 
was to investigate the effect of playing the proposed game on enhancing children's knowledge of healthy diet and lifestyle. We proposed and described the design, implementation, and preliminary evaluation of Diabetic Mario Bros, a mobile game intended to engage and motivate children to adopt a healthy lifestyle, which would enable them to take increasing control of their condition. The contributions of this work were: (1) proposing a novel game design for teaching children how to manage diabetes; (2) applying the proposed design to an open-source 2D game and developing a mobile version; (3) evaluating the effect of playing the game on enhancing children's knowledge of healthy diet and lifestyle; and (4) introducing four heuristics that are specifically designed to evaluate educational mobile games and using those heuristics to study our participants' perception of playing the game over a period of 1 week.

We uncovered several interesting observations. The results show that the participants enjoyed playing the game. They also believed that it would have added educational value, as it involved players in problem-solving and decision making, by requiring them to balance food and exercise to keep Mario's blood sugar level (displayed throughout the game) within the optimal levels. The results also showed that playing the game for a week enhanced children's diabetes health-related knowledge, which in turn can stimulate and facilitate the conversation of the children with healthcare providers about their self-management practices.

However, there were a few limitations in terms of players' competence and health background. The current version of the game does not take the history of the player into account and all users are presented with the same challenges regardless of their gaming experience. The core research effort going forward will focus on effects on engagement and health knowledge changes as a result of personalization technology in computer games. Personalizing the game according to players' preferences and abilities can sustain their engagement in the long term and encourage them to use and explore all features supported by the system. Research also shows the importance of positive feedback as the key to increasing player's motivation. ${ }^{31}$ There is music playing continuously in our game while it is being played, but it does not necessarily provide feedback, for example, cheering the player if they perform well. In addition, for the purpose of this study, participants were not required to have diabetes mellitus, nor had to have any particular experience playing videogames of any time. For the next evaluation study, we will be recruiting children with type I diabetes.

Given the usability feedback and feature request from participants, we aim to refine the game and include the ability for it to save interaction sessions, so when the user logs in they will not have to start from Level 1 each time. We will also look at further analyzing the player interaction data logged on each tablet, such as the number of sessions, duration of each session, the amount of food items consumed, blood sugar levels, number of feedback messages given etc., which would allow us to gauge the extent to which the game design successfully embeds enjoyable experiences and meaningful learning outcomes. Analysis of the interaction data will also allow us to think in terms of what motivates a participant to play a health educational mobile game and how that motivation can be sustained over time. We also plan to study the effectiveness of the proposed game design on long-term behavioral changes and increased knowledge of diabetes self-management. We believe our research paves the way for the systematic design and development of fullfledged computer games dedicated to diabetes education in the future.

\section{Author Disclosure Statement}

No competing financial interests and/or associations that pose real or perceived conflicts of interest in connection with the article exist.

\section{References}

1. Diabetes and Cardiovascular Disease Quality Improvement Plan. Wellington: Ministry of Health; 2008. https:// www.health.govt.nz/system/files/documents/publications/ diabetes-cardio-quality-improvement-plan-feb08-v2.pdf

2. Baranowski T, Baranowski J, Thompson D, et al. Video game play, child diet, and physical activity behavior change: A randomized clinical trial. Am J Prev Med 2011; 40:33-38.

3. Raaff C, Glazebrook C, Wharrad H. A systematic review of interactive multimedia interventions to promote children's communication with health professionals: Implications for communicating with overweight children. BMC Med Inform Decis Mak 2014; 14:8.

4. Greysen SR, Khanna RR, Jacolbia R, et al. Tablet computers for hospitalized patients: A pilot study to improve inpatient engagement. J Hosp Med 2014; 9:396-399.

5. Chen G, Baghaei N, Sarrafzadeh A, et al. Designing games to educate diabetic children. In: Proceedings of the 23rd Australian Computer-Human Interaction Conference; Canberra, Australia. 2011, pp. 72-75.

6. Malone TTW. Heuristics for designing enjoyable user interfaces: Lessons from computer games. In: CHI '82 Proceedings of the 1982 Conference on Human Factors in Computing Systems; New York: ACM Press, 1982, pp. 63-68.

7. Clanton C. An interpreted demonstration of computer game design. Most 1998; 7-8.

8. Federoff MA. Heuristics and usability guidelines for the creation and evaluation of fun in video games. FUN in Video Games [MS Thesis]. Graduate School of Indiana University; December 2002, p. 52.

9. Desurvire H, Blvd W, Rey M, Caplan M. Using Heuristics to Evaluate the Playability of Games. Defense 2004 8:1509-1512.

10. Korhonen H, Koivisto EMI. Playability heuristics for mobile games. In Proceedings of the 8th Conference on Human-Computer Interaction with Mobile Devices and Services (Helsinki, Finland). ACM, 2006, pp. 9-16.

11. Korhonen H, Koivisto EMI. Playability heuristics for mobile multi-player games. In: Proceedings of the $2 \mathrm{nd}$ Int Conference on Digital Interactive Media in Entertainment and Arts; Perth, Australia. 2007, pp. 28-35.

12. Schaffer N. Heuristics for Usability in Games. 2007, pp. 130. www.playerfriendly.com (accessed March 1, 2016).

13. Pinelle D, Wong N, Stach T. Heuristic evaluation for games: Usability principles for video game design. In: Proceeding of the Twenty-sixth Annual SIGCHI Conference on Human Factors in Computing Systems; Florence, Italy. 2008, pp. 1453-1462

14. Pinelle D, Wong N, Stach T, Gutwin C. Usability heuristics for networked multiplayer games. In: Proceedings of the ACM; 2009 International Conference on Supporting Group Work (GROUP 2009), Sanibel Island, FL, 2009, pp. 169-178 
15. Ibrahim A, Gutiérrez Vela, FL, González Sánchez, JL, et al. Educational playability analyzing player experiences in educational video games. In: ACHI 2012, The Fifth International Conference on Advances in Computer-Human Interactions; 2012, pp. 326-335.

16. Soomro S, Ahmad WFW, Sulaiman S. A preliminary study on heuristics for mobile games. In: 2012 International Conference on Computer \& Information Science (ICCIS); 2012, pp. 1030-1035.

17. Shoukry L, Sturm C, Galal-Edeen GH. Pre-MEGa: A Proposed Framework for the Design and Evaluation of Preschoolers' Mobile Educational Games. In: Innovations and Advances in Computing, Informatics, Systems Sciences, Networking and Engineering; 2015, pp. 385-390.

18. Kirriemuir J. A Survey of the use of computer and video games in classrooms. Internal Report for British Educational Communications and Technology Agency, 2002. http://www.digra.org/wp-content/uploads/digital-library/ 05150.28025.pdf

19. Csikszentmihalyi M. Flow: The Psychology of Optimal Experience. New York: Harper \& Row; 1990.

20. Malone T. What Makes Things Fun to Learn? A Study of Intrinsically Motivating Computer Games. Palo Alto: Xerox; 1980.

21. Mankoff J, Dey AK, Hsieh G, et al. Heuristic evaluation of ambient displays. In: Proceedings of the SIGCHI Conference on Human Factors in Computing Systems; Ft. Lauderdale, FL, 2003, pp. 169-176.

22. Korhonen H. The explanatory power of playability heuristics. In: Proceedings of the 8th International Conference on Advances in Computer Entertainment Technology; Lisbon, Portugal, 2011, p. 40.

23. Lugmayr A. (Ed.). Media in the Ubiquitous Era: Ambient, Social and Gaming Media: Ambient, Social and Gaming Media. Hershey, PA: IGI Global; 2011.

24. Zaman HB, Robinson P, Olivier P, et al. Advances in Visual Informatics: Third International Visual Informatics Conference, IVIC 2013, Malaysia, November 2013; pp. 13-15.

25. Nacke LE, Drachen A, Göbel, S. Methods for evaluating gameplay experience in a serious gaming context. Int J Comput Sci Sport 2010; 9:1-12.

26. Chai CS, Koh E, Lim CP, Tsai CC. Deepening ICT integration through multilevel design of technological pedagogical content knowledge. J Comput Educ 2014; 1:1-17.

27. Saksvig BI, Gittelsohn J, Harris SB, et al. A pilot schoolbased healthy eating and physical activity intervention improves diet, food knowledge, and self-efficacy for native Canadian children. J Nutr 2005; 135:2392-2398.
28. Edmundson E, Parcel GS, Feldman HA, et al. The effects of the child and adolescent trial for cardiovascular health upon psychosocial determinants of diet and physical activity behavior. Prev Med 1996; 25:442-454.

29. Macaulay AC, Paradis G, Potvin L, et al. The Kahnawake Schools Diabetes Prevention Project: Intervention, evaluation, and baseline results of a diabetes primary prevention program with a native community in Canada. Prev Med 1997; 26:779-790.

30. Lieberman DA. Digital games for health behavior change: Research, design, and future directions. In: eHealth Applications: Promising Strategies for Behavior Change. Noar SM, Harrington NG (eds.). New York: Routledge; 2012, pp. 110-127.

31. Przybylski AK, Rigby C, Ryan RM. A motivational model of video game engagement. Rev Gen Psychol 2010; 14: 154-166.

32. Hendrikx M, Meijer S, Van Der Velden J, Iosup A. Procedural content generation for games: A survey. ACM Transact Multimedia Comput Commun Appl 2013; 9:1.

33. Pedersen C, Togelius J, Yannakakis GN. Modeling player experience for content creation. IEEE Transact Comput Intelligence AI Games 2010; 2:54-67.

34. Thompson D. Designing serious video games for health behavior change: Current status and future directions. J Diabetes Sci Technol 2012; 6:807-811.

35. Rigby S, Ryan RM. Glued to Games: How Video Games Draw Us In and Hold Us Spellbound. Santa Barbara, CA: ABC-CLIO; 2011.

36. Chik A. Digital gaming and language learning: Autonomy and community. Lang Learn Technol 2014; 18:85.

37. de Freitas SI. Using games and simulations for supporting learning. Learn Media Technol 2006; 31:4, 343-358.

38. Jeong E, Kim D. Definitions, key characteristics, and generations of mobile games. In: Encyclopedia of Mobile Computing and Commerce. Taniar D (ed.). Idea Group Reference, 2007; pp. 185-189.

Address correspondence to: Nilufar Baghaei, PhD

Unitec Institute of Technology Private Bag 92025

Victoria Street West Auckland 1142 New Zealand

E-mail: nbaghaei@unitec.ac.nz 